[Agr. Biol. Chem., Vol. 33, No. 1, p. 63 68, 1969]

\title{
Studies on the Utilization of Hydrocarbons by Microorganisms
}

\author{
Part XII. Screening of Alicyclic Hydrocarbon-Assimilating \\ Microorganisms and trans-4-Ethylcyclohexanol \\ Formation from Ethylcyclohexane
}

\author{
By Yoshiaki Arai and Koichi Yamada \\ Department of Agricultural Chemistry, Faculty of Agriculture, \\ The University of Tokyo \\ Received May 17, 1968
}

\begin{abstract}
In the course of investigation of alicyclic hydrocarbon-utilizing microorganisms, five strains of ethylcyclohexane-utilizing bacteria were isolated from soil samples.

Among those bacteria, the strain S6Bl that was identified as Alcaligenes faecalis, showed the best growth in shaking culture.

The strain S6BI was found to produce 4-ethylcyclohexanol from ethylcyclohexane.

This substance separated from culture broth was purified and identified to be trans-4ethylcyclohexanol by the use of NMR.
\end{abstract}

According to the advance of petroleum microbiology, many reports have been published as to the intermediates or end products accumulated during the microbial dissimilation of hydrocarbons. However, most of them were concerned with aliphatic or aromatic hydrocarbons and as to alicyclic hydrocarbons there are only a few reports, i.e., the formation of valeric acid, ${ }^{11}$ formic acid, cyclohexanol and adipic acid from cyclohexane; the formation of adipic acid from decalin; ${ }^{21}$ the co-oxidation of $n$-butylcyclohexane to cyclohexane-acetic-acid $^{3)}$ and the co-oxidation of several cycloparaffines to alicyclic monoketones. ${ }^{4 \prime}$

This report deals with the isolation of alicylic hydrocarbon-utilizing microorganisms,

1) B. Imelik, Compt. Rend. Acad. Sci., 226, 2082 (1948).

2) C. Colla and V. Treccani, Ann. Microbiol. ed Enzimol., 10, 77 (1960).

3) J. B. Davis and R. L. Raymond, Appl. Microbiol., 9, 383 (1961).

4) J. Ooyama and J. W. Foster, Antonie van Leeuzuonhoek, 31, 45 (1965). the taxonomical studies of isolated bacteria and microbial formation of trans-4-ethylcyclohexanol from ethylcyclohexane.

\section{MATERIALS AND METHODS}

Microorganisms. Five strains of bacteria were isolated from soil samples, using alicyclic hydrocarbons as the main source of carbon.

With regard to the microorganism that showed the best growth in shaking culture, diagnostic tests were carried out according to the "Manual of Microbiological methods," 1957, Society of American Bacteriologists and "Bergey's Manual of Determinative Bacteriology," 7th Ed., 1957.

Medium. The medium contained, per liter of distilled water, $1.0 \mathrm{~g} \mathrm{NH}_{4} \mathrm{NO}_{3}, 1.5 \mathrm{~g} \mathrm{KH}_{2} \mathrm{PO}_{4}, 1.5 \mathrm{~g}$ $\mathrm{Na}_{2} \mathrm{HPO}_{4}, \quad 0.2 \mathrm{~g} \mathrm{MgSO} \cdot 7 \mathrm{H}_{2} \mathrm{O}, 0.01 \mathrm{~g} \mathrm{CaCl} \cdot 2 \mathrm{H}_{2} \mathrm{O}$, $0.005 \mathrm{~g} \mathrm{FeSO}_{4} \cdot 7 \mathrm{H}_{2} \mathrm{O}, 0.002 \mathrm{~g} \quad \mathrm{MnSO}_{4} \cdot 4 \mathrm{H}_{2} \mathrm{O}, 0.05 \mathrm{~g}$ yeast extract and $\mathrm{pH}$ was adjusted to 7.0. A test tube ( $200 \mathrm{~mm}, 18 \mathrm{~mm}$ inner diameter) containing $5 \mathrm{ml}$ of the medium was autoclaved at $115^{\circ} \mathrm{C}$ for 10 min and used for the screening of microorganisms. Before cultivation $0.1 \mathrm{ml}$ of separately sterilized hydrocarbon was added to $5 \mathrm{ml}$ of the medium. A 
5 liters-shaking-flask containing 1 liter of the medium was used for the detection of the products.

Cultivation. For the detection of products a loopful of cells grown on hydrocarbon-agar-slant for 3 days was inoculated into $40 \mathrm{ml}$ of the liquid medium which was shaken for 3 to 4 days at $30^{\circ} \mathrm{C}$. Then this seed culture was transferred into 5 liter-shakingflask containing 1 liter of the medium.

Hydrocarbons Cyclohexane, cyclohexanone, cyclohexene, methycyclohexane, ethylcyclohexane and decalin were used as the carbon sources.

They were purchesed from Tokyo Chemical Industry Co., Ltd. Tokyo.

4-Ethylcyclohexanol (mixture of cis- and transisomers) was purched from $\mathrm{K} \& \mathrm{~K}$ Laboratories, Inc. New York.

\section{Analytical methods and apparatus}

Thin layer chromatography. Thin layer chromatography using silicagel $G$ was employed for the detection of the metabolic products.

Solvent systems used are listed in Table $\mathrm{I}$. The spots were visualized by spraying $\mathrm{H}_{2} \mathrm{SO}_{4}$ (containing $0.5 \mathrm{~g}$ of $\mathrm{KMnO}_{4}$ in $15 \mathrm{ml}$ ).

Silicagel $\mathrm{G}$ was obtained from E. Merck Co., Ltd. Darmstadt.

\section{TABLe I. SOLVEnT Systems for SIlicagel G THIN LAYER CHROMatography}
a) Benzene-ethanol
$10: 1$
b) Benzene-acetic acid
$10: 1$
c) Carbon tetrochloride-acetic acid-water
$10: 1: 1$
d) Methanol saturated heptane

Column chromatography. Silicic acid column chromatography was employed for the purification of the product and the separation of cis- and transisomers of authentic 4-ethylcyclohexanol.

Solvent system was benzene-ethylacetate. Column was $300 \mathrm{~mm}$ in length and $20 \mathrm{~mm}$ inner diameter.

Silicic acid was obtained from Mallinkrodt Chemical Works, New York.

Gas-liquid chromatography. Gas-liquid chromatography was performed with a model $\mathrm{K}-53$ Hitachi Seisakusho Ltd., using $4 \mathrm{~mm} \times 2 \mathrm{~m}$ column packed with 10\% PEG 1500 on diasolid (60 80 mesh). The operating conditions were as follows;

column temperature: $175^{\circ} \mathrm{C}$

carrier gas helium

flow rate $\quad: 40 \mathrm{ml} / \mathrm{min}$

detector : thermal conductivity detector

Infrared spectra. The infrared absorption spectra were obtained on film with a Model IR-S infrared Spectrophotometer, Japan Spectroscopic Co., Ltd.

Mass spectra. Mass spectra were obtained by a model RMU-6D mass spectrometer with direct inlet system at $70 \mathrm{eV}$ of electron accelerating voltage.

Nuclear magnetic resonance spectra. NMR spectra were obtained with a JEOL- $4 \mathrm{H}-100$ spectrometer at $100 \mathrm{mc}$.

\section{RESULTS}

\section{Isolation of microorganisms}

Enrichment culture with $0.1 \mathrm{~g}$ of a soil sample and $5 \mathrm{ml}$ of the medium in a test was carried out at $30^{\circ} \mathrm{C}$ for 3 to 4 days.

Microorganisms were isolated after two successive enrichment cultures by the method shown in Fig. 1.

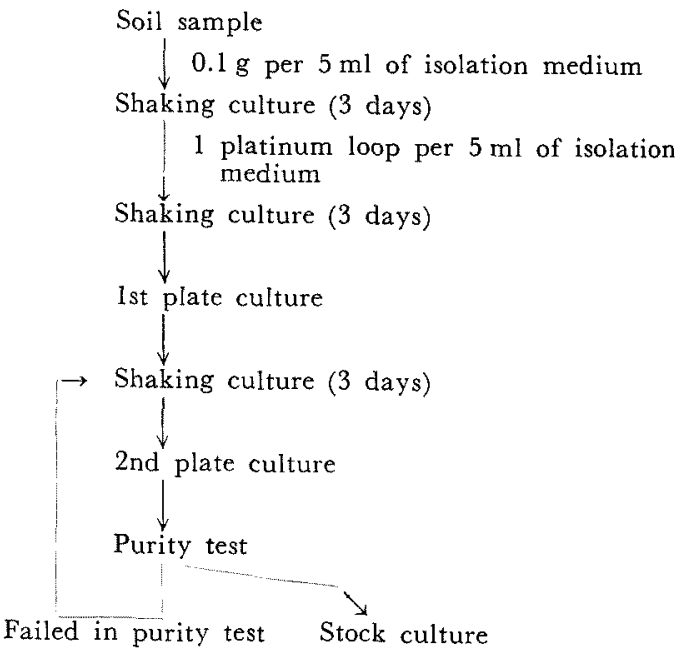

FIG. 1. Isolation Method of Bacteria. 
From 350 soil samples 5 bacterial strains that grew on ethylcyclohexane as the main source of carbon were isolated.

Strain S6Bl showed the best growth in liquid culture.

\section{Taxonomical studies of strain $S 6 B 1$}

The results of taxonomical studies are shown in Table II. Based on the description in the 7th edition of Bergey's Manual, the strain $\mathrm{S} 6 \mathrm{~B} 1$ was identified as Alcaligenes faccalis.

\section{TABle II. Descriptive Chart of Strain S6BI}

Rods, 0.4 to 0.6 by 1.2 to 1.8 microns. Motile with peritrichous flagella. Gram-negative.

Nutrient agar colonies: Circular, smooth, entire, raised, opaque, glistening, pale yellowish brown, bityrous.

Nutrient agar slant: Growth moderate, filiform, glistening, yellowish gray, medium unchanged.

Nutrient broth: Strongly turbid.

Nutrient gelatin stab: No liquefaction.

Milk: Unchanged.

B.C.P. milk: Slightly alkaline, not peptonized.

Nitrite produced from nitrate.

Nitrate respiration: Positive.

Indole not produced.

MR test: Negative.

V-P test: Negative.

Starch not hydrolyzed.

Hydrogen sulfide not produced.

No acid and gas from glycerol, xylose, glucose, sucrose, lactose and starch in both aerobic and anaerobic conditions.

Citrate and succinate are utilized as a sole soruce of carbon with ammoniacal nitrogen, but glucose, gluconate, $p$-hydroxybenzoate and protocatechuate are not utilized.

Grows well at $20^{\circ}$ to $30^{\circ}$ No growth at $42^{\circ}$

\section{Separation of metabolic product $A$}

The ether extract of $72 \mathrm{hr}$ culture broth of the strain S6B1 was applied to silicagel G thin layer chromatography.

Four spots were detected on the thin layer plate by using benzene-ethanol $(10: 1)$ as solvent system and $\mathrm{H}_{2} \mathrm{SO}_{4}$ (containing $0.5 \mathrm{~g}$ of $\mathrm{KMnSO}_{4}$ in $15 \mathrm{ml}$ ) for spraying reagent.

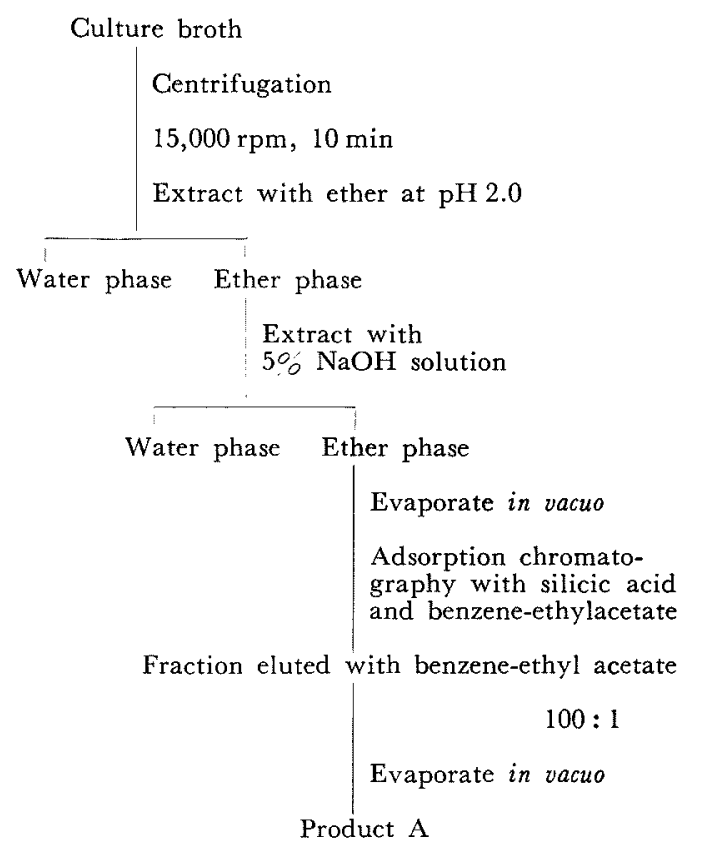

FIG. 2. Isolation Procedure for Product A.

The ether extract was treated according to the procedure presented in Fig. 2 and the main product $\mathrm{A}$ was purified.

\section{Analysis of product $A$}

Purified product A was colorless, transparent, neutral liquid, soluble in ether, benzene, ethylacetate, ethanol, and insoluble in water. It gave a single spot on the thin layer chromatogram by using solvent systems shown in Table I.

Mass spectrum of this substance revealed a parent ion peak of $m / e 178$ with composition $\mathrm{C}_{8} \mathrm{H}_{16} \mathrm{O}$. The presence of the functional groups illustrated in Table III was expected on the basis of infrared spectra and nuclear magnetic resonance spectra. Considering that ethylcyclohexane was used as the main source of carbon, these data suggest that this substance is ethylcyclohexanol. Among four isomers of ethylcyclohexanol, the product $\mathrm{A}$ will be 2 ethyl-, 3 ethyl- or 4 ethylcyclohexanol. 
TABLE III. ASSUMED FUNCTIONAL GROUPS ON THE BASIS OF INFRARED SPECTRA AND NuClear Magnetic RESONANCE SPECTRA

$\begin{array}{lcc} & \mathrm{IR}, \nu\left(\begin{array}{l}\mathrm{Film} \\ \mathrm{max}\end{array}\right) \mathrm{cm}^{-1} & \mathrm{NMR}, \tau\left(\begin{array}{l}\mathrm{Me}_{4} \mathrm{Si} \\ \mathrm{CDCl}_{3}\end{array}\right) \\ -\mathrm{CH}_{2} \mathrm{CH}_{3} & 3330,1055 & 9.12(3 \mathrm{H}, \mathrm{t}) \\ >\mathrm{CHOH} & & 6.5 \mathrm{~L}(1 \mathrm{H}, \mathrm{m}) \\ -\mathrm{CH}_{3},-\mathrm{CH}_{2}- & 2920,2840 & \\ >\mathrm{C}=\mathrm{C}< & 1450,1370 & \end{array}$

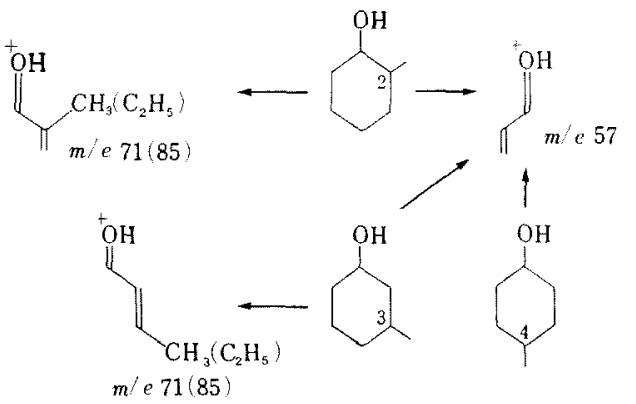

FIG. 3. Predicted Fission Modes of Mass Spectra of Methylcyclohexanol and Ethylcyclohexanol.

According to the Herbert Budzikiewicz's information concerning mass spectra of methylcyclohexanol, ${ }^{51}$ 2-methyl and 3-methylcyclohexanols have two types of fission modes and 4-methylcyclohexanol has only one type as shown in Fig. 3 as demonstrated in Table IV. Ethylcyclohexanol is expected to have similar fission mode to methylcyclohexanol because of structural similarity. Therefore, it is suggested that the product A must be 4-ethylcyclohexanol considering the relative abundance of $m / e 57$ and $m / e 84$ ions in the mass spectra.

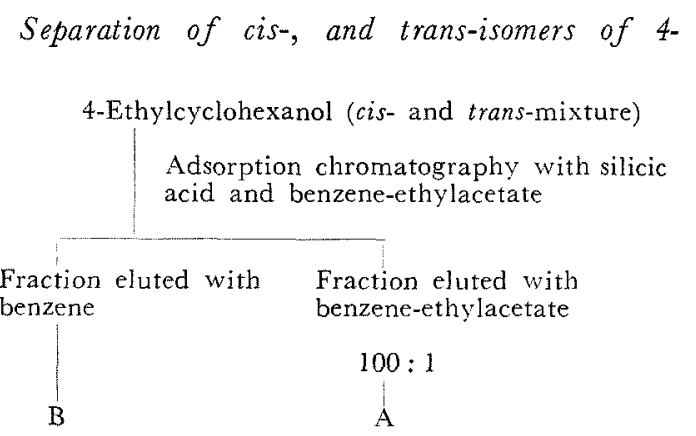

FIG. 4. Separation of cis-, and trans-Isomers of 4Ethylcyclohexanol.

Table IV. Relative ABUNdance of $m / e$ 57, AND $m / e 71$ IONS OF METHYLCYClOHEXANOL, AND m/e 57 AND $m / e$ 84 IONS OF PRODUCT A

Relative abundance of $m / e 57$ and 71 ions of methylcyclohexanol

\begin{tabular}{|c|c|c|}
\hline & $m / e 57$ & $m / e 71$ \\
\hline 2-Methylcyclohexanol & 69 & 31 \\
\hline 3-Methylcyclohexanol & 36 & 64 \\
\hline 4-Methylcyclohexanol & 90 & 10 \\
\hline
\end{tabular}

Relative abundance of $m_{i} e 57$ and 85 ions of product $A$

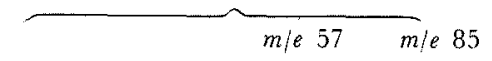

Product A 85

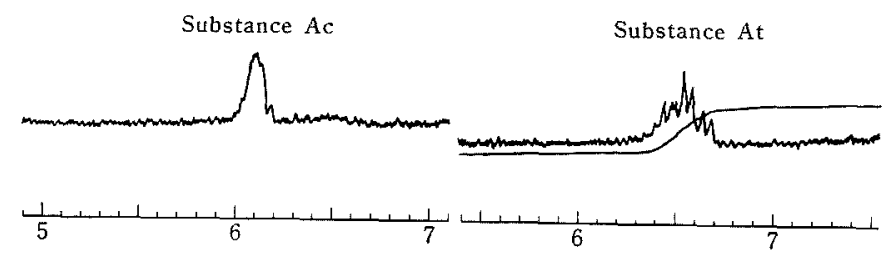

FIG. 5. Nuclear Magnetic Resonance Spectra of Substance A and B.

5) "Interpretation of Mass Spectra of Organic Compounds," ed. by H. Budzikiewicz, C. Djerassi and D. H. Williams, Holden-Day Inc., San Francisco. 1964, P. 39. 


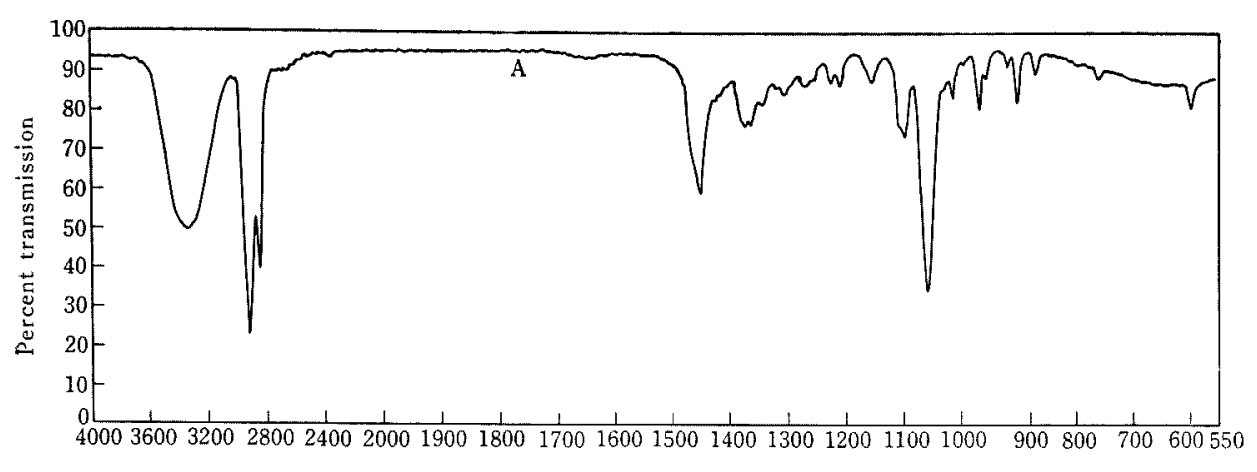

A

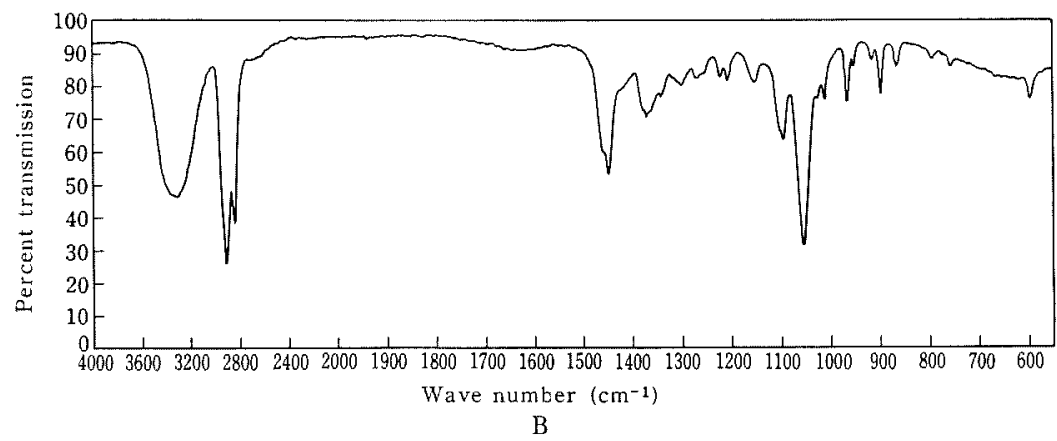

FIG. 6. Infrared Spectra of Product A.

A: Product A

B: Authentic trans-4-ethylcyclohexanol

\section{ethylcyclohexanol.}

Cis- and trans-isomers of 4-ethylcyclohexanol were separated according to the procedure presented in Fig. 4.

Substance $\mathrm{A}$ and $\mathrm{B}$ was determined to be trans- and cis-isomers respectively with nuclear magnetic resonance spectra shown in Fig. 5.

Multiplex signals in the $\tau 6$ to $\tau 7$ region seem to show the spin-spin coupling of 1 hydrogen with the four hydrogens on the neighboring carbons. Comparing the halfwidth $50 \mathrm{cps}$ and $20 \mathrm{cps}$ of the two signals, substance A seemed to be trans-isomer and substance B cis-isomer. ${ }^{6 \prime}$

6) R. U. Lemieux, R. K. Kullning, H.J. Bernstein and W. G. Schneider, J. Am. Chem. Soc., 80, 6093 (1958).

\section{Identification of trans-4-ethylcyclohexanol}

The purified sample showed the identical $R f$ value in thin layer chromatography with solvent systems shown in Table I, retention time of 2.4 min under the condition previously listed, infrared spectrum shown in Fig. 6, and mass spectrum with those of trans-4ethylcyclohexanol separated according to the procedure shown in Fig. 4.

\section{SUMMARY}

1. Five strains of bacteria were isolated from soil samples with ethylcyclohexane as the main source of carbon.

2. The strain S6Bl which showed the best growth in the liquid medium was identified 
as Alcaligenes faecalis.

3. The main product was separated from culture broth and identified as trans-4-ethylcyclohexanol.

4. The mixture of trans- and cis-isomers of 4-ethylcyclohexanol was separated and submitted to the identification.

Acknowledgement. Grateful acknowledgement is made to Dr. K. Komagata for the taxonomical studies, and Dr. N. Takahashi for suggestion on the identification of the product. 